\title{
HUBUNGAN KADAR GULA DARAH SEWAKTU DENGAN PROSES PENYEMBUHAN LUKA PADA PASIEN POST SECTIO CAESAREA DI RSU IPI MEDAN
}

\author{
Sarmaida Siregar \\ Universitas Imelda Medan, Jl. Bilal No. 52 Kelurahan Pulo Brayan Darat I Kecamatan Medan Timur, \\ Medan - Sumatera Utara. \\ E-mail: sarmaidabahtiar.123@gmail.com
}

\begin{abstract}
ABSTRAK
Sectio caesarea dilakukan untuk mengeluarkan satu atau lebih bayi dari rahim ibu. Salah satu faktor yang mempengaruhi penyembuhan luka yaitu kadar gula darah yang dapat menghambat leukosit melakukan fagositosis sehingga rentan terhadap infeksi oleh karena itu jika mengalami luka akan sulit sembuh. Rumusan masalah penelitian adalah bagaimana hubungan kadar gula darah sewaktu dengan proses penyembuhan luka pada pasien post sectio caesarea. Tujuan penelitian untuk menganalisis hubungan kadar gula darah sewaktu dengan proses penyembuhan luka pada pasien post sectio caesarea. Jenis penelitian adalah korelasi dengan pendekatan cross sectional yang dilaksanakan di RSU IPI Medan. Sampel penelitian seluruh ibu post sectio caesarea tiga hari sebesar 77 orang. Alat pengumpulan data menggunakan lembar observasi kadar gula darah dan lembar observasi penyembuhan luka. Uji yang digunakan adalah chi-square. Hasil penelitian menunjukkan Ada hubungan yang signifikan antara kadar gula darah normal dengan penyembuhan luka sectio caesarea ( $p$ value < 0,05) dengan Rasio Prevalensi $(R P)=12,1$ artinya kadar gula darah yang hiperglikemi pada ibu post sectio caesarea mempunyai risiko 12,1 kali ibu mengalami infeksi pada luka operasi dibandingkan dengan kadar gula darah yang normal. Disarankan kepada ibu post sectio caesarea lebih aktif dalam mencari informasi tentang cara mengontrol kadar gula darah yang baik agar mendukung proses penyembuhan luka untuk mencegah infeksi pada pasien post sectio caesarea.
\end{abstract}

\section{Kata Kunci: Kadar gula darah, Penyembuhan luka, Post sectio caesarea.}

\section{ABSTACT}

Sectio caesarea is done to remove one or more babies from the mother's womb. One of the factors that influence wound healing is blood sugar levels that can inhibit leukocytes from phagocytosis making them susceptible to infection. The research problem formulation is how the relationship between blood sugar levels while with the healing process of wounds in post sectio caesarea patients. The purpose of this study was to analyze the relationship between blood sugar levels during the wound healing process in postsectio caesarea patients. This type of research is the correlation with the cross sectional approach carried out at IPU Medan General Hospital. The study sample of all mothers post sectio caesarea three days by 77 people. Data collection tools using blood sugar level observation sheets and wound healing observation sheets. The test used was chi-square. The results showed there was a significant relationship between normal blood sugar levels with wound healing in caesarean section ( $p$ value <0.05) with a Prevalence Ratio $(R P)=12.1$ meaning that hyperglycemic blood sugar levels in post sectio caesarean mothers had a risk of 12, 1 time the mother has an infection in the surgical wound compared to normal blood sugar levels. It is recommended that post sectio caesarean mothers be more active in finding information about controlling good blood sugar levels in order to support the wound healing process to prevent infection in post sectio caesarean patients.

Keywords: Blood Sugar Levels, Wound Healing, Post Sectio Caesarea.

\section{PENDAHULUAN}

Sectio Caesarea (SC) merupakan suatu prosedur pembedahan dimana dilakukan sayatan pada abdomen dan uterus. Pembedahan tersebut dilakukan untuk mengeluarkan bayi dari rahim ibu. Sectio caesarea dilakukan bila ada indikasi persalinan pervaginam yang dapat membahayakan keselamatan ibu ataupun bayi. Namun beberapa pasien melakukan SC berdasarkan keinginan mereka sendiri tanpa adanya indikasi medis, namun World Health Organization (WHO) menyarankan agar persalinan SC hanya dilakukan berdasarkan indikasi medis saja (WHO, 2015). 
Berdasarkan data dari rekam medis RS Imelda Medan periode Januari - Desember tahun 2018 jumlah persalinan dengan tindakan SC sebanyak 1.150 kasus dengan indikasi medis yang diperoleh adalah partus tak maju, previous sectio caesarea, postdate, cephalo pelvic disproportion (CPD), ketuban pecah dini dan beberapa diantaranya dilakukan tanpa indikasi medis.

Prosedur SC merupakan penyebab luka sayat atau iris yang disebut juga Vulnus scissum. Luka ini terlihat tepi luka berupa garis lurus dan beraturan (Bakkara, 2012). Proses penyembuhan luka SC dapat terjadi secara normal tanpa bantuan, namun beberapa bahan perawatan dapat membantu untuk mendukung proses penyembuhan. Bahan pelindung tersebut dapat melindungi area luka agar bebas dari kotoran dengan menjaga kebersihan dan dapat membantu untuk meningkatkan penyembuhan jaringan (Walyani, 2015).

Penyembuhan luka menurut Wound Healing Society (WHS) sebagai suatu yang kompleks dan dinamis sebagai akibat dari pengembalian kontinuitas dan fungsi anatomi. Pada luka bedah dapat dilihat adanya sintesis kolagen dengan melihat adanya jembatan penyembuhan dibawah jahitan yang mulai menyatu. Jembatan penyembuhan nampak pada hari 5-7 post operasi (Bakkara, 2012). Penyembuhan luka merupakan hal yang harus diperhatikan karena bila penyembuhan luka tidak sempurna bisa membahayakan pasien. Seperti terjadinya infeksi yang kemudian menyebabkan sepsis, dan bila penyembuhan luka melambat (menjadi lebih lama) akan menyebabkan aktivitas pasien menjadi tergangggu (Heryani, 2012).

Ada faktor-faktor yang mempengaruhi kesembuhan luka. Ada yang mempercepat dan memperlambat kesembuhan luka. Hal yang mempercepat kesembuhan luka antara lain: usia muda, nutrisi, tidak adanya infeksi, sirkulasi dan oksigenasi, keadaan luka, obat. Hal yang memperlambat penyembuhan luka dibagi dua, faktor intrinsik dan faktor ekstrinsik. Faktor intrinsik meliputi respon inflamasi yang berkaitan dengan infeksi sedangkan faktor ekstrinsik meliputi : malnutrisi, usia tua, merokok, penggunaan steroid dan hiperglikemi (Suryadi et al, 2013) Hiperglikemi dapat menghambat leukosit melakukan fagositosis sehingga rentan terhadap infeksi oleh karena itu jika mengalami luka akan sulit sembuh (Alduna, 2013). Hiperglikemi menyebabkan lamanya proses penyembuhan luka karena adanya gangguan sintesa kolagen, angiogenesis dan fagositosis. Peningkatan kadar glukosa juga dapat mengganggu transport sel asam askorbat kedalaman bermacam sel termasuk fibroblast dan sel darah putih. Peningkatan kadar glukosa darah juga dapat menurunkan leukosit kemotaktis, arterosklerosis, khususnya pembuluh darah kecil, juga pada gangguan suplai oksigen jaringan (Khudin, 2014) Hiperglikemi dapat diperiksa menggunakan pemeriksaan sederhana yaitu dengan pemeriksaan kadar glukosa darah sewaktu. Disamping itu juga diperoleh melalui proses glukoneogenesis dan glikogenolisis (Murray et al, 2009).

Penelitian sebelumnya yang berkaitan dengan tindakan perawatan luka dengan kepuasan pasien post operasi menyatakan adanya hubungan yang signifikan antara tindakan perawatan luka dengan kepuasan pasien post operasi. Dalam hal ini perawat harus memberikan tindakan perawatan luka post operasi pada pasien agar pasien merasa puas dan senang selama proses perawatan luka post operasi (Siagian, 2016).

Penelitian lain yang berjudul "Hubungan Status Nutrisi Dengan Waktu Penyembuhan Luka Pada Pasien Post Apendiktomi Di Rumah Sakit Kota Medan" menyatakan Asupan nutrisi yang baik dapat menentukan waktu penyembuhan luka post apendiktomi. Diharapkan kepada petugas kesehatan memonitor status nutrisi pada pasien post operasi untuk dapat mengoptimalkan fase penyembuhan luka (Hasibuan, 2018).

Dari penelitian ini diharapkan setelah operasi sectio caesarea pasien juga di kontrol gula darahnya agar proses penyembuhan luka juga maksimal tanpa adanya infeksi. Karena masih banyak permasalahan infeksi yang terjadi pada post operasi sectio caesarea. Sehingga untuk mengetahui apakah ada hubungan antara angka GDS dengan kesembuhan luka post sectio caesarea diperlukan adanya penelitian ini untuk meminimalisir kejadian infeksi.

Berdasarkan survey awal pada 02 April 2019 di RSU IPI Medan, data rekam medik menunjukkan jumlah pasien sectio caesarea 
dari bulan Januari sampai Desember 2018 sebanyak 1.150 orang $(61,2 \%)$ dan persalinan normal sebanyak 729 orang $(38,8 \%)$. Jadi, rata-rata persalinan SC perbulan sebanyak 96 orang (Sistem Informasi Rumah Sakit/SIRS, 2018).

\section{METODE PENELITIAN}

Tujuan penelitian untuk menganalisis hubungan kadar glukosa darah sewaktu dengan proses penyembuhan luka post operasi SC. Penelitian ini menggunakan desain korelasi dengan pendekatan pengamatan sewaktu (cross sectional). Populasi penelitian adalah seluruh ibu post sectio caesarea di RSU IPI Medan dengan menggunakan metode purposive sampling sebanyak 77 responden. Alat pengumpulan data menggunakan lembar observasi kadar gula darah sewaktu lembar penyembuhan luka menurut REEDA Scale. Analisis data menggunakan uji chi square.

\section{HASIL}

Tabel 1. Karakteristik Ibu Post Sectio Caesarea Berdasarkan Umur, Pendidikan,

Paritas, BMI, Riwayat Penyakit Penyerta di RSU IPI Medan

\begin{tabular}{clcc}
\hline No & Karakteristik & f & \% \\
\hline 1. & Umur (Tahun) & & \\
\hline & $21-30$ & 38 & 49,4 \\
\hline & $31-40$ & 39 & 50,6 \\
\hline & Total & 77 & 100 \\
\hline 2. & Pendidikan & & \\
\hline & SMP & 23 & 29,9 \\
\hline SMA & 49 & 63,6 \\
\hline PT & 5 & 6,5 \\
\hline Total & 77 & 100 \\
\hline 3. & Paritas & & \\
\hline & Primipara & 34 & 44,2 \\
\hline & Multipara & 43 & 55,8 \\
\hline & Total & 77 & 100 \\
\hline 4. & BMI & \\
\hline & $<23 \mathrm{Kg} / \mathrm{m}^{2}$ & 7 & 9,1 \\
\hline & $\geq 23 \mathrm{Kg} / \mathrm{m}^{2}$ & 70 & 90,9 \\
\hline
\end{tabular}

\begin{tabular}{|c|c|c|c|}
\hline & Total & 77 & 100 \\
\hline 5. & \multicolumn{3}{|c|}{ Riwayat Penyakit Penyerta } \\
\hline & Tidak ada & 72 & 93,5 \\
\hline & Anemia & 3 & 3,9 \\
\hline & Diabetes melitus & 2 & 2,6 \\
\hline & Total & 77 & 100 \\
\hline
\end{tabular}

Dari tabel 1 diatas dapat dilihat bahwa dari $77 \mathrm{ibu}$ post SC lebih dari setengah berumur 31-40 tahun sebanyak 39 orang $(50,6 \%)$, berdasarkan pendidikan lebih dari setengah lulusan SMA sebanyak 49 orang $(63,6 \%)$, berdasarkan paritas lebih dari setengah multipara sebanyak 43 orang $(55,8 \%)$, BMI sebagian besar $\geq 23 \mathrm{~kg} / \mathrm{m} 2$ sebanyak 70 orang $(90,9 \%)$, dan berdasarkan riwayat penyakit penyerta hampir seluruhnya tidak ada sebanyak 72 orang $(93,5 \%)$.

Tabel 2. Distribusi Frekuensi Kadar Glukosa Darah Sewaktu di RSU IPI Medan

\begin{tabular}{ccc}
\hline $\begin{array}{c}\text { Kategori Kadar } \\
\text { Gula Darah } \\
\text { Sewaktu }\end{array}$ & f & $\%$ \\
\hline Normal & 62 & 80,5 \\
\hline Hiperglikemi & 15 & 19,5 \\
\hline
\end{tabular}

Dari tabel 2 diatas dapat dilihat bahwa responden dengan kadar GDS 1 normal ada 62 orang atau $80,5 \%$ dari seluruh responden dan yang hiperglikemi ada 15 orang atau $19,5 \%$ dari seluruh responden.

Tabel 3. Distribusi Frekuensi Penyembuhan Luka Sectio Caesarea di RSU IPI Medan

Penyembuhan Luka $\quad$ f $\quad \%$ Sectio Caesarea

\begin{tabular}{lll} 
Normal & 53 & 68,8 \\
\hline Infeksi ringan & 24 & 31,2 \\
\hline
\end{tabular}

Dari tabel 3 diatas dapat dilihat bahwa dari $77 \mathrm{ibu}$ post sectio caesarea hari ketiga setengah ibu mengalami proses penyembuhan luka post section caesarea normal sebanyak 53 orang $(68,8 \%)$ dan hampir seperempat ibu mengalami proses penyembuhan luka post section caesarea infeksi ringan sebanyak 37 orang $(20,0 \%)$.

Tabel 4. Hubungan Kadar Gula Darah Sewaktu dengan Penyembuhan Luka Sectio Caesarea di RSU IPI Medan

\begin{tabular}{|c|c|c|c|c|c|c|c|c|}
\hline \multirow{3}{*}{ Variabel } & \multicolumn{6}{|c|}{ Penyembuhan Luka Sectio Caesarea } & \multirow{3}{*}{$\mathrm{P}$} & \multirow{3}{*}{$p$} \\
\hline & \multicolumn{2}{|c|}{ Normal } & \multicolumn{2}{|c|}{ Infeksi Ringan } & \multicolumn{2}{|c|}{ Total } & & \\
\hline & $\mathbf{n}$ & $\%$ & $\mathbf{n}$ & $\%$ & $\mathbf{n}$ & $\%$ & & \\
\hline \multicolumn{9}{|c|}{ Kadar Gula Darah Sewaktu } \\
\hline Normal & 3 & 5,5 & 9 & 14,5 & 2 & 00 & \multirow{2}{*}{2,1} & \multirow{2}{*}{0,000} \\
\hline Hiperglikemi & 1 & 7,1 & 14 & 92,9 & 5 & 00 & & \\
\hline
\end{tabular}


Dari tabel 4 diatas dapat dilihat bahwa dari hubungan antara kadar gula darah dengan penyembuhan luka sectio caesarea diperoleh bahwa dari 62 ibu yang memiliki kadar gula darah sewaktu normal, ada sebanyak 9 orang $(14,5 \%)$ yang mengalami infeksi ringan, sedangkan diantara ibu yang memiliki kadar gula darah sewaktu hiperglikemi, ada 14 orang $(92,9 \%)$ post sectio caesarea hari ketiga dengan proses penyembuhan luka mengalami infeksi ringan. Hasil uji statistik didapatkan nilai $p$ value $=$ 0,000 , yang berarti ada hubungan yang signifikan antara kadar gula darah sewaktu dengan proses penyembuhan luka post sectio caesarea ( $p$ value < 0,05). Hasil analisis diperoleh Rasio Prevalensi $(\mathrm{RP})=12,1$ artinya kadar gula darah sewaktu yang hipoglikemi pada ibu post sectio caesarea mempunyai risiko 12,1 kali ibu mengalami infeksi pada luka operasi dibandingkan dengan kadar gula darah sewaktu yang normal.

\section{PEMBAHASAN}

Kadar Glukosa Darah pada Ibu Post Sectio Caesarea

Berdasarkan hasil analisis univariat, diketahui bahwa responden dengan kadar glukosa darah sewaktu normal ada 62 orang atau $80,5 \%$ dari seluruh responden dan yang hiperglikemi ada 15 orang atau $19,5 \%$ dari seluruh responden. Dimana karakteristik ibu post SC yaitu dari ibu post SC lebih dari setengah berumur 31-40 tahun sebanyak 39 orang $(50,6 \%)$, berdasarkan pendidikan sebagian besar lulusan SMA sebanyak 49 orang $(63,6 \%)$, berdasarkan paritas sebagian besar multipara sebanyak 43 orang $(55,8 \%)$, BMI sebagian besar $\geq 23 \mathrm{~kg} / \mathrm{m}^{2}$ sebanyak 70 orang $(90,9 \%)$, dan berdasarkan riwayat penyakit penyerta hampir seluruhnya tidak ada. Menurut Maryanto (2013), Hiperglikemi menyebabkan lamanya proses penyembuhan luka karena adanya gangguan sintesa kolagen, angiogenesis dan fagositosis. Peningkatan kadar glukosa juga dapat mengganggu transport sel asam askorbat kedalaman bermacam sel termasuk fibroblast dan leukosit. Hiperglikemi juga dapat menurunkan leukosit kemotaktis, arterosklerosis, kususnya pembuluh darah kecil, juga pada gangguan suplai oksigen jaringan. sebanyak 72 orang $(93,5 \%)$.
Dari penelitian ini diharapkan setelah operasi sectio caesarea pasien juga di kontrol gula darahnya agar proses penyembuhan luka juga maksimal tanpa adanya infeksi. Karena masih banyak permasalahan infeksi yang terjadi pada post operasi sectio caesarea. Sehingga untuk mengetahui apakah ada hubungan antara angka gula darah sewaktu dengan kesembuhan luka post sectio caesarea diperlukan adanya penelitian ini untuk meminimalisir kejadian infeksi.

\section{Hubungan Kadar Glukosa Darah dengan Penyembuhan Luka pada Ibu Post Sectio Caesarea}

Berdasarkan hasil analisis bivariat, hubungan antara Kadar Gula Darah dengan penyembuhan luka sectio caesarea diperoleh bahwa dari 62 ibu yang kadar gula darah sewaktunya normal, ada sebanyak 9 orang $(14,5 \%)$ yang mengalami infeksi ringan, sedangkan diantara ibu yang dengan kadar gula darah sewaktu hiperglikemi, ada 14 orang $(92,9 \%)$ post sectio caesarea hari ketiga dengan proses penyembuhan luka mengalami infeksi ringan. Hasil uji statistik didapatkan nilai $p$ value $=0,000$, yang berarti ada hubungan yang signifikan antara kadar gula darah dengan proses penyembuhan luka post sectio caesarea ( $p$ value $<0,05)$. Hasil analisis diperoleh Rasio Prevalensi (RP) = 12,1 artinya kadar gula darah yang tidak normal pada ibu post sectio caesarea mempunyai risiko 12,1 kali ibu mengalami infeksi pada luka operasi dibandingkan dengan kadar gula darah sewaktu normal

Hasil penelitian ini sesuai dengan penelitian yang dilakukan oleh Puspitasari et $a l$, menemukan bahwa diabetes mellitus yaitu penyakit dengan kadar glukosa darah tinggi atau hiperglikemi ada hubungannya dengan penyembuhan luka post operasi Sectio caesarea. Selain penelitian tersebut ada penelitian oleh Nurani et al (2015), yang menyebutkan bahwa penyembuhan luka sectio caesarea ada hubungannya dengan diabetes mellitus.

\section{KESIMPULAN}

Berdasarkan hasil penelitian dapat disimpulkan ada hubungan antara kadar glukosa darah dengan penyembuhan luka sectio caesarea ( $p$ value $<0,05)$. Hasil analisis diperoleh Rasio Prevalensi (RP) = 
12,1 artinya kadar gula darah yang hiperglikemi pada ibu post SC mempunyai risiko 12,1 kali ibu mengalami infeksi pada luka operasi dibandingkan dengan kadar glukosa darah yang normal.

\section{DAFTAR PUSTAKA}

Alduna, F, (2013), Pasien Sectio Caesarea Di RSUP. H. Adam Malik Medan Tahun 2009 2011 , repository.usu.ac.id/bitstream/12345678 9/37949/4/ Chapter\%20II.pdf.

Bakkara, C.J. (2012). Pengaruh Perawatan Luka Bersih Menggunakan Sodium Clorida 0,9\% dan Povidine Iodine 10\% Terhadap Penyembuhan Luka Post Appendiktomi di RSU Kota Tanjung Pinang Kepulauan Riau repository.usu.ac.id/bitstream/12345678 9/31496/6/Chapter\%20II.pdf. Di akses tanggal 18 Juni 2018.

Heryani, R. (2012). Asuhan Kebidanan Ibu Nifas dan Menyusui. Jakarta: CV Trans Info Medika.

Khudin, M.K. (2014). Hubungan Kadar Gula Darah Sewaktu dengan Kejadian Stroke Iskemik Ulang di Rumah Sakit Umum Daerah. Karya Tulis Ilmiah strata satu, Universitas Muhammadiyah Surakarta, Surakarta.

Maryanto, A. (2013). Pengaruh Kadar Albumin Serum Terhadap Lamanya Penyembuhan Luka Operasi. Tesis, Universitas Gajah Mada, Yogyakarta.

Murray et al., (2009). Biokimia Harper. 27th ed. Jakarta : EGC.
Nurani, D., Keintjem, F., \& Losu, F.N. (2015). Faktor-Faktor yang Berhubungan dengan Proses Penyembuhan Luka Post Sectio Caesarea. Jurnal Ilmiah Bidan. Volume 3. Nomor 1.

Hasibuan, M. T. D. (2018). HUBUNGAN STATUS NUTRISI DENGAN WAKTU PENYEMBUHAN LUKA PADA PASIEN POST APENDIKTOMI DI RUMAH SAKIT KOTA MEDAN. Jurnal Ilmiah Keperawatan Imelda, 4(1), 58-61. http://jurnal.uimedan.ac.id/index.php/JU RNALKEPERAWATAN

Siagian, hartika samgryce. (2016). Hubungan tindakan perawatan luka dengan kepuasan pasien post operasi di ruang rawat inap rsu sidikalang tahun 2011. Jurnal Ilmiah Keperawatan Imelda, 2(2), 143-150. http://jurnal.uimedan.ac.id/index.php/JU RNALKEPERAWATAN/article/view/2 $49 / 252$

Suryadi, et al. (2013). Proses Penyembuhan dan Penanganan Luka. http://download.portalgaruda.org/article. php? article $=14468 \&$ val $=970$.

WHO. (2015). World Health Statistic Report 2015. Geneva: World Health Organization.

Walyani, S.E. (2015). Asuhan Kebidanan Masa Nifas \& Menyusui. Yogyakarta: Pustaka Baru Press. 